\title{
Gestão democrática e a educação profissional e tecnológica a partir dos pressupostos freireanos
}

\section{Democratic management and vocational and technological education based on paulo freire's assumptions La gestión democrática en la educación profesional y tecnológica a partir de los presupuestos freireanos}

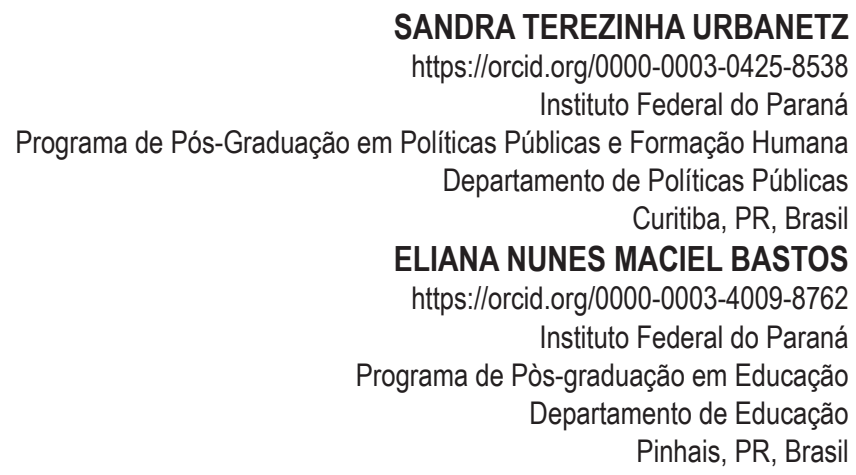

\begin{abstract}
Resumo: O texto destaca a gestão democrática como premissa para a realização de uma educação mais igualitária nos âmbitos da educação nacional, principalmente, na ambiência da Educação Profissional e Tecnológica (Ept). Demonstrando os subsídios legais vigentes e os indicativos de Paulo Freire para a constituição de uma gestão democrática. Têm-se o objetivo de aguçar as discussões acerca da postura participativa e/ou democrática das gestões escolares contemporâneas, a partir dos pressupostos Freireanos, os quais são imprescindíveis quando se almeja constituir uma educação integral qualitativa.
\end{abstract}

Palavras-chave: Gestão Democrática. Paulo Freire. Educação Profissional. Democracia.

Abstract: The text highlights the democratic management as a premise for the achievement of a more equal schooling in national education, mainly in Vocational and Technological Education (Ept). It aims to boost discussions on the participatory and/or democratic posture of contemporary school management by showing the current legal subsidies and Paulo Freire's assumptions for the building of a democratic management, which are essential when constituting a qualitative complete education.

Keywords: Democratic Management. Paulo Freire. Vocational Education. Democracy. 
Resumen: El texto destaca la gestión democrática como premisa para la realización de una educación más igualitaria en los ámbitos de la educación nacional, principalmente en el ambiente de la Educación Profesional y Tecnológica (EPT), demostrando los subsidios legales vigentes y los indicativos de Paulo Freire para la constitución de una gestión democrática. El objetivo es el de aguzar las discusiones acerca de la postura participativa y / o democrática de las gestiones escolares contemporáneas, a partir de los presupuestos freireanos, los cuales son imprescindibles cuando se anhela constituir una educación integral cualitativa.

Palabras clave: Gestión democrática. Paulo Freire. Educación Profesional. Democracia.

\section{INTRODUÇÃO}

Os pressupostos de Paulo Freire para a gestão escolar, os quais dão indicativos exitosos para uma prática educacional mais justa e igualitária, explicitam a possibilidade da efetivação da gestão democrática nas ambiências educacionais da Educação Profissional e Tecnológica (Ept) a partir das suas implicações benéficas para a construção de uma educação integral, posto que, mais do que nunca, discutir sobre a democracia faz-se muito relevante diante das realidades das escolas brasileiras inseridas numa sociedade com tantas diversidades e adversidades, vítima de tantos retrocessos, como bem nos lembra Frigotto (2017):

O Brasil, no contexto do capitalismo mundial, estruturou-se sob o signo colonizador e escravocrata e, como tal, produziu uma das sociedades mais desiguais e violentas do mundo. Das burguesias clássicas que lutaram para constituir nações autônomas e independentes e que, mesmo cindidas em classes, estruturaram sociedades com acesso aos direitos sociais básicos, diferentemente dessas, a burguesia brasileira sempre foi antinação, antipovo, antidireiro universal à escola pública. Uma burguesia sempre associada de forma subordinada aos centros hegemônicos do capital. A desigualdade econômica, social, educacional e cultural que se explicita em pleno século XXI resulta de um processo de ditaduras e golpes da classe dominante com objetivo de manter seus privilégios. Ao longo do século XX convivemos, por mais de um terço do mesmo, com ditaduras e submetidos a seguidos golpes institucionais como mecanismos de impedir avanços das lutas populares e da classe trabalhadora na busca dos direitos elementares do acesso à terra, comida, habitação, saúde, educação e cultura. (FRIGOTTO, 2017, p. 21).

Depreende-se que a sociedade brasileira ainda está em processo de aprendizagem, no que diz respeito a exercer de fato, a democracia. Muitos avanços têm sido alcançados desde a promulgação da Constituição de 1988, porém, é certo que em pleno século XXI ainda são muitos os dilemas evidentes numa sociedade em que os seus cidadãos não têm plena consciência de seus papéis em uma democracia. 
Perante tais indagações é coerente dizer que a escola precisa discutir e viver a democracia, para tanto, a gestão precisa propagar os benefícios de agir democraticamente, os educandos precisam aprender a respeitar e exercer a democracia mediante suas vivências de aprendizes como cidadãos, e assim por diante, precisamos sem sombra de dúvidas, dialogar sobre a importância de vivermos numa sociedade democrática.

A partir da Lei ${ }^{\circ} 11.892$, sancionada em 29 de dezembro do ano de 2008, que criou 38 Institutos Federais de Educação, Ciência e Tecnologia (IFET) espalhados pelo Brasil, muitas pesquisas começaram a ficar mais interessadas para as temáticas relacionadas a EPT, como formação do docente da educação profissional e tecnológica, os impactos sobre a sociedade e também sobre os modelos de organização e gestão. Essa institucionalidade apresenta desafios em todos os âmbitos para a gestão, posto que os Institutos Federais ofertam desde cursos de curta duração para formação inicial e/ ou continuada até programas de mestrado, indicando desafios para a construção de uma gestão democrática dentro de um espaço educativo que pode atender tanto o jovem, quase adolescente que inicia a sua formação profissional nos cursos técnicos integrados, quanto os adultos, atendidos pela educação de Jovens e Adultos (EJA) ou estudantes dos cursos de formação inicial e/ou continuada (FIC) ou ainda estudantes nos cursos de graduação e pós graduação.

Os ensinamentos de Paulo Freire nos instigam a debater sobre a democracia na nossa escola contemporânea porque "os regimes autoritários são em si uma contradição, uma negação profunda da natureza do ser humano, que, indigente, inconcluso, necessita da liberdade para ser, como o pássaro precisa do horizonte para voar.” (FREIRE, 2003, p. 205).

A Lei de Diretrizes e Bases da Educação Nacional (LDBEN -1996) traz em seu Artigo $3^{\circ}$ os princípios para a Educação Nacional, especificamente, no Inciso VIII explicita-se como um dos princípios: "a gestão democrática do ensino público, na forma desta Lei e da legislação dos sistemas de ensino.” E mais adiante no Artigo 14 da LDBEN fica designado:

Art. 14. Os sistemas de ensino definirão as normas da gestão democrática do ensino público na educação básica, de acordo com as suas peculiaridades e conforme os seguintes princípios:

I - participação dos profissionais da educação na elaboração do projeto pedagógico da escola;

II - participação das comunidades escolar e local em conselhos escolares ou equivalentes. (BRASIL, 2018, p. 15). 
Ainda no campo das legislações destaca-se a definição de gestão democrática que consta nas Diretrizes Curriculares Nacionais da Educação Básica (DCNs): "A gestão democrática é entendida como princípio que orienta os processos e procedimentos administrativos e pedagógicos, no âmbito da escola e nas suas relações com os demais órgãos do sistema educativo de que faz parte." (BRASIL, 2013, p. 56).

Destaca-se também a Lei no 13.005/2014 - Plano Nacional de Educação (PNE), que em sua "meta 19" traz a especificidade da gestão democrática, como algo primordial para a constituição de uma educação pública de qualidade em todo o território nacional. Sendo este mais um fato que corrobora para a prática democrática nos ínterins dos espaços escolares, buscando sempre propagar discussões que viabilizem novas e inovadoras maneiras de fazer uma educação equitativa, gerenciando os espaços de aprendizagem pelo prisma da democracia.

Kunze (2009) explica que [...] a criação da rede federal de educação profissional no Brasil [...] ocorreu ao final de 1910, quando o governo federal cria e instala em cada capital brasileira uma Escola de Aprendizes Artífices, tendo como principal objetivo ministrar o ensino de ofícios referentes às necessidades e especialidades industriais de cada Estado, proporcionando uma profissão aos chamados ociosos e desprovidos da sorte e da fortuna. Ou seja, era necessário oferecer um ofício, a fim de formar os futuros operários necessários e úteis às indústrias que nasciam no país. Esse conjunto de escolas profissionais foi concebido no âmbito das propostas voltadas à consolidação da República Federativa Brasileira, com vistas ao progresso, que na concepção vigente estava fortemente vinculada à necessidade de educação do povo, juntamente com a industrialização e ao controle social.

Pode-se inferir então que a gestão das escolas de Aprendizes e Artífices não nasce com uma marca de gestão democrática colocando para a EPT um desafio histórico. 


\title{
OS INDICATIVOS DE PAULO FREIRE PARA A GESTÃO DEMOCRÁTICA
}

\begin{abstract}
Ensinar democracia é possível, mas não é tarefa para quem se desencanta da terça para a quarta-feira somente porque as nuvens ficaram pesadas e ameaçadoras. Ensinar democracia é possível, mas não é tarefa para quem pensa que o mundo se refaz na cabeça das pessoas bem-intencionadas.

Ensinar democracia é possível, mas não é tarefa para quem só paciente, espera tanto que perde o "trem da história", como não é tarefa para quem, só impaciente, põe a perder seu próprio sonho.

Ensinar democracia é possível, mas não é tarefa para quem percebe a história e nela atua mecanicistamente, para os voluntaristas, "donos" da história. (FREIRE, 2003, p. 202).
\end{abstract}

Ao inspirar-nos nas ideias freireanas referente às ações democráticas, as quais são instrumentos eficazes na realização de uma gestão mais igualitária dentro dos espaços públicos educativos nos dias contemporâneos, a partir da experiência gestora no SESI (Serviço Social da Indústria), Freire (2003, p. 115) diz que: "Em 1947, cheguei ao Serviço Social da Indústria, Sesi, Departamento Regional de Pernambuco, onde permaneceria por dez anos, envolvido numa prática políticopedagógica da mais alta importância para mim".

A prática político-pedagógica é a principal característica da gestão democrática, na qual está intrínseco o fazer educativo diário construído com as pessoas, com todos e todas que compõem o espaço educacional. Este é o principal ponto a ser discutido sobre a gestão escolar, que se acredita ser o ideal de professores e professoras do século XXI, numa perspectiva de atender ao legado propagado por Paulo Freire em seus exemplos como gestor, bem como em seus escritos que se perpetuam e disseminam-se até hoje, sendo tão atuais, desafiando os profissionais da educação a repensarem suas práticas cotidianamente, a fim de conduzir os processos educativos para a construção de conhecimentos que sejam revolucionários e eficazes na concepção de cidadãos, que estejam engajados na construção de uma sociedade menos desigual.

As ações que compõem a gestão do espaço educativo precisam ser alicerçadas na arte do diálogo, primando pela participação de todos os colaboradores de tal espaço, sem exceção. É preciso dar voz e vez às pessoas, pois são estas que fazem a ambiência educativa acontecer de fato.

Gerir o espaço escolar em uma perspectiva político-pedagógica requer esforço em fazer acontecer processos de aprendizagens que sejam concisos, todos os processos administrativos, burocráticos, ou seja, todas as tarefas que perpassam pelos cotidianos dos espaços educacionais precisam convergir na construção de um processo de ensino e aprendizagem, o qual seja coerente com 
as reais necessidades dos educandos, sendo que estes são, ou devem ser, o objeto central do trabalho da gestão, entendendo que toda a gestão escolar é realizada para que haja aprendizagem significativa aos educandos.

Para Freire (2003), a construção de uma escola democrática consiste, em linhas gerais, na superação da mera transmissão de conteúdo ou da memorização de conhecimentos, sendo que os educandos devem ser veementemente estimulados a pensar com autonomia, instigados a agir em suas ambiências educativas por intermédio de suas expressões: falando, gesticulando, escrevendo, interagindo, etc. $\mathrm{O}$ educando precisa exercer sua liberdade dentro do processo de ensino e aprendizagem, mediado por professores e professoras que estejam preparados técnica e teoricamente, que possam dialogar também com autonomia, comprometimento diante do conhecimento que anseia-se construir com eficácia. Para tanto, é necessário que a gestão democrática pense e faça movimentos em prol da formação continuada dos profissionais da educação, incluindo todos os trabalhadores do espaço escolar, para que seja compreendido que todos, sem exceção, são partes dos processos que convergem no ensino do educando, assim as práticas democráticas são, essencialmente, participativas, não têm como pensar em uma gestão democrática individualizada ou isolada.

O arcabouço da gestão democrática pode ser caracterizado nas "experiências de organização, de ingerência, de análise crítica dos fatos. Experiências de decisão que, no fundo, inexiste fora da prova a que nos submetem os conflitos, da comparação, da valoração, da ruptura, da opção." (FREIRE, 2003, P. 122). Com essa explicação infere-se que a democratização da gestão escolar acontece na prática, ou seja, a reflexão ou avaliação da prática gestora deve acontecer constantemente, sendo por meios sistematizados ou, naturalmente, ouvindo as pessoas, conversando com os trabalhadores dos espaços educativos, com os educandos, com os professores, com as famílias etc. Entende-se que Freire (2003) deixa-nos os indicativos de que só é possível conceber uma gestão democrática se há humildade por parte dos gestores em prosseguir cotidianamente, corrigindo as ações em prol do atendimento integral às pessoas que estão inseridas dentro do espaço educacional, fazendo com que tais pessoas se sintam coparticipantes dos processos que integram o todo escolar.

É certo que todos os papéis que integram o fazer de um gestor contemporâneo na Ept são por vezes diversos e/ou contraditórios a uma prática mais participativa com todos os colaboradores do espaço educativo, devido à urgência dos prazos de alguns processos administrativos e em outros momentos a morosidade dos afazeres burocráticos, sendo assim, é preciso obter coerência 
em dialogar o máximo possível com os seus semelhantes, promovendo a transparência das ações gestoras. Para tanto, Freire (2003) relata que para realizar uma administração fundamentalmente democrática é preciso:

Uma gestão tanto quanto possível aberta à ingerência dos educandos e suas famílias em diferentes níveis, com que fossem eles aprendendo democracia pela prática da participação. Aprendendo democracia pela experiência da decisão, da crítica, da denúncia, do anúncio. (FREIRE, 2003, p. 123) \{Grifos nossos\}.

O agir democrático é feito na ação e reflexão das práticas constituídas, é no desenrolar das relações educativas, é no ato de reunir os funcionários da escola para as reuniões bimestrais, por exemplo, e dar voz e vez aos sujeitos, ouvindo-os, debatendo sobre os temas pertinentes ao bom funcionamento do espaço escolar, demonstrando, assim, por parte da gestão, o interesse genuíno na participação de todos em prol do êxito na realização dos processos que constituem o específico ambiente educativo.

A democracia é algo que está sendo aprendido ainda pelos partícipes da sociedade vigente. Então, necessita ser exercitada com os educandos, com os professores, com as famílias, precisa ser debatida a temática, a fim de compreender os papéis de cada sujeito nos processos de fazer uma educação menos desigual, e tal processo de aprendizagem democrático só pode acontecer se houver vontade política de seus personagens. E essa vontade política no contexto educativo consiste na maneira de ser, na maneira de agir, na maneira de olhar o semelhante, na maneira de conduzir as falas no dia a dia do contexto escolar, ou seja, o sujeito precisa entender que o seu papel é singular, único e muito importante na constituição da identidade escolar, a fim de que se consigam os resultados satisfatórios mediante a formação dos educandos da vigente escola. Todos estão envolvidos em um só processo: o de educar para transformar as vidas dos educandos, e, consequentemente, tais vidas são responsáveis em interferir na transformação de suas sociedades.

Acreditar que a nossa postura individual faz total diferença na concepção de um grupo mais democrático é primordial para a aquisição de uma coletividade concisa, a qual esteja em busca, verdadeiramente, de um espaço escolar democrático. Contudo, os sujeitos precisam se sentir valorizados, participantes da construção da escola, para isto é preciso praticar a dialogicidade, a humildade, a reflexão.

Portanto, nos espaços democráticos deve-se assegurar “(...) o direito à fala, à voz, o direito à crítica, resguardado também o direito de cada um ao respeito de todos. (FREIRE, 2003, p. 139). 
Depreende-se que os profissionais da gestão educacional precisam estar dispostos a aprender constantemente a democracia e propagar a importância dos atos democráticos para toda sua equipe, fazendo com que todos, sem exceção, pratiquem o respeito mútuo em seus cotidianos, valorizando a participação dos seus pares nas decisões do funcionamento da escola, no que tange as suas funções. A fim de que haja clareza nas ações estabelecidas dentro dos espaços escolares, corroborando, assim, para a constituição de ambientes que sejam cada vez mais harmonizados e propícios para a realização de processos educativos exitosos.

Freire (2003) nos dá indicativos para a realização de uma gestão democrática nos espaços educacionais, porém, não são "receitas prontas", pois cada espaço educativo é singular, constituído por pessoas diversas, as quais dão as características peculiares para cada ambiência escolar. Contudo, o autor faz uma advertência quanto à postura do gestor sublinhando que ele não tem "o direito de mentir, de ser incoerente, de ter medo de concordar com o oponente se este me convencer do seu acerto." (FREIRE, 2003, p. 141).

Indubitavelmente, a postura do gestor é determinante para contagiar sua equipe em prol da democratização do espaço educativo, lembrando que este é um processo, o qual deve ser aprendido diariamente, de acordo com as realidades peculiares dos espaços educacionais, pois cada um possui suas características singulares em virtude da diversidade de pessoas que os constituem. E estas devem entender também a relevância da participação de todos na constituição de um espaço escolar que atenda às necessidades reais de seus educandos, convergindo com os anseios de seus profissionais e de sua comunidade. Portanto, "Como relação democrática, o diálogo é a possibilidade de que disponho de, abrindo-me ao pensar dos outros, não fenecer no isolamento.” (FREIRE, 1992, p. 61). Para primar pela coletividade, a gestão democrática deve se abrir ao diálogo e este deve acontecer nas ações da escuta, da humildade, da fala mansa, da argumentação consistente, da pesquisa constante, enfim, da postura humana e respeitosa diante dos semelhantes.

A gestão democrática precisa considerar todo o contexto da sua escola, ou seja, o interior e exterior que compõem tal ambiência educativa, conhecendo o seu público interno (educandos, professores e funcionários) e externo (famílias dos educandos), a fim de que aconteçam diálogos promissores entre os partícipes. Diante disso, Freire (2003) indica que: 
A aprendizagem dos educandos tem a ver com as dificuldades que eles enfrentam em casa, com as possibilidades de que dispõem para comer, para vestir, dormir, para brincar, com as facilidades ou com os obstáculos à experiência intelectual. Tem que ver com sua saúde, com seu equilíbrio emocional. A aprendizagem dos educandos tem que ver com a docência dos professores e professoras, com sua seriedade, com sua competência científica, com sua amorosidade, com seu humor, com sua clareza política, com sua coerência, assim como todas estas qualidades têm que ver com a maneira mais ou menos justa ou decente com que são respeitados ou não. (FREIRE, 2003, p. 126).

Pensar numa prática político-pedagógica da gestão implica agir sob os fundamentos de uma educação libertadora, denominada por Paulo Freire em seus escritos em tantos momentos, compreendendo esta prática libertadora como a propagadora de condições para que os sujeitos aprendam com autonomia, constituindo-se protagonistas de suas histórias, cidadãos conscientes de seus mundos. Assim, entende-se que a responsabilidade de uma gestão libertadora consiste em valorizar todos os seus sujeitos, dando voz e vez a todos, e, na medida do possível, alcançar os anseios de todos, no que diz respeito aos objetivos da escolarização democrática do educando em questão.

Pautados nos fundamentos de um fazer educacional libertador é possível mudar as concepções, os costumes, que por vezes indicam as práticas autoritárias de educação, por exemplo. As mudanças são possíveis na educação quando geridas por pessoas que acreditam em seus potenciais, mas também que possuem consciências de suas limitações diante das organizações exacerbadas da sistematização capitalista. Nesse sentido, a inspiração dos ideais libertadores propostos por Paulo Freire não são de maneira nenhuma ingênuos, sobretudo, contribuem para que se reflita acerca das realidades postas pelos paradigmas vigentes, e, a partir da compreensão do mundo que permeia os indivíduos, construir novas aprendizagens, as quais possam ser instrumentos para as feituras de diversas possibilidades em um contexto inovador de um mundo em que as pessoas sejam mais solidárias, críticas, autônomas, conscientes, humanas, generosas, humildes, acolhedoras, éticas; enfim, quiçá sejam cooperadoras para a construção de uma sociedade menos injusta.

É mister sonhar e refletir, idealizar e agir, porém, como Freire (2003, p. 136) adverte: "É bem verdade, enfatizemos, que não vale, por outro lado, a prática educativa que fique apenas na denúncia e no anúncio, no alumbramento em face do sonho, e se esqueça ou minimize a preparação técnica, a instrumentação para o trabalho. "Não se pode conceber uma prática educacional desligada da pesquisa constante e do estudo responsável frente às questões que são relevantes no fazer educacional, é importantíssimo que as pessoas estejam preparadas da melhor maneira possível para cumprirem os seus papéis com êxitos nos âmbitos educativos. 
Sendo assim, é relevante sublinhar a necessidade da formação continuada para todos os profissionais da educação, iniciando nos gestores e perpassando por todos os funcionários da escola. O papel de aprender é constante na vida das pessoas que fazem a educação acontecer nos ínterins dos espaços escolares.

Para que o gestor democrático exerça a democracia de fato em seu espaço escolar, é necessário que saiba ouvir, tendo uma escuta atenta aos seus partícipes e tal postura requer sabedoria, como também é preciso argumentar, respondendo com satisfação os seus semelhantes. Para tanto, o conhecimento é primordial, e a constituição do saber sobre sua prática só pode ser feita mediante o estudo, a pesquisa, a preparação, a formação incessante do profissional, pois, acredita-se na premissa freireana que designa os humanos como “(...) seres finitos, inacabados, homens e mulheres vimos sendo seres vocacionados para ser mais." (FREIRE, 2003, p. 192). E nessa perspectiva da busca do "Ser Mais" é necessário revestir-se de humildade, sendo perspicaz em busca dos conhecimentos cabíveis para gerir os espaços escolares com maestria, lidando com as pessoas da melhor maneira possível mediante cada realidade, a fim de ser um agente de mudanças em seus ambientes de atuação.

$\mathrm{Na}$ experiência de Freire vivida no SESI destaca-se um relato, o qual faz refletir sobre a importância da escuta atenta nos cotidianos que permeiam os espaços escolares:

\begin{abstract}
$\mathrm{Na}$ busca de superação de nossos erros e equívocos foi de extraordinária importância a crítica amena, até cortês, que nos fez, a mim e as meus companheiros e companheiras de equipe, um pai de aluno nosso de um dos núcleos do Sesi do Recife. Terminara de falar sobre o dever que a escola tem de respeitar o saber com que o aluno a ela chega. Sentado na primeira fila, em frente a nós, estava o ainda bem moço pai, que desinibido, se levanta e fala: "Se me perguntam se eu gostei desta reunião, eu não vou dizer que não, por causa de que aprendi umas coisas das palavras do doutor. Mas, se perguntam se era isso que queria ouvir hoje, eu digo que não. Eu queria ouvir hoje era umas palavra de expricação sobre disciprina, por causa de que eu tou tendo em casa, eu e minha mulher, problema com os menino e não sei resolver." (FREIRE, 2003, p. 127).
\end{abstract}

Tal relato nos indica a necessidade do gestor ser resiliente, ou seja, saber se portar diante do seu público, escutar os anseios das famílias e com elas encontrar maneiras de que sejam sanados tais anseios, ou pelo menos engajar-se em busca de resoluções para os problemas que as famílias indicam na constituição da educação dos seus filhos, sendo que o trabalho de ensino e aprendizagem é inteiramente afetado pelo desenvolvimento das relações que os educandos possuem com os seus pares em suas famílias, as condições concretas em que vivem, assim por diante. 
Outro ponto que o relato do pai acima nos instiga a pensar é a importância de organizar, como gestores democráticos, formações teóricas e práticas que possam ser relevantes para as famílias, trazendo-as na medida do possível para os interiores das nossas escolas, possibilitando diálogos virtuosos em virtude de aprendizagens que sejam revolucionárias, levando as pessoas a conhecerem suas realidades e assim, possam conscientemente, transformá-las através do poder do conhecimento.

É fácil dar abertura ao diálogo? Ouvir as vozes das famílias? Escutar as vozes dos funcionários? Atentar-se às vozes dos educandos? Obviamente, a prática dialógica nos âmbitos educacionais desafia a postura dos gestores, e é, justamente, este ponto desafiador que instiga a necessidade de se pensar a educação de maneira inovadora, respeitando as características de cada ambiente escolar, construindo a identidade coletiva da escola com todos os semelhantes, exercendo como gestor da educação a postura da escuta e mediar, conforme as realidades e com muito bom senso, as ações possíveis no seu ambiente de atuação, lembrando sempre de valorizar o ser humano essencialmente, respeitando todos os semelhantes como coparticipantes dos processos escolares, agindo assim, com a maior clareza.

Destacar-se-á o exemplo do zelador Francisco, que Freire (2003) descreve:

Vale a pena agora relembrar a emoção e a segurança com que Francisco, o zelador mais velho, falou e o impacto que suas palavras provocaram. "Não tenho muito o que dizer, começou ele, " de um dia meu de trabalho, no DR (Departamento Regional do Sesi). Sou um simples zelador fazendo serventias, limpando salas, mesas, comprando cigarro pra os doutores, servindo o café, levando documentos de uma sala para a outra. Desde que soube que hoje ia falar pra tanta gente, de memória e de leitura, que eu comecei a perguntar o que é um dia meu de trabalho e de vida. É muita coisa. Primeiro, porque, juntando um dia com o outro, eu encho o mês e ganho, com suor, o sustento meu e de minha família. Segundo, porque sem trabalho não sei viver. Meu dia é um dia como o de milhares de brasileiros como eu e melhor do que o dia de outros milhares, que nem o pouco que eu tenho eles têm. Estou contente com o meu dia a dia. Sou humilde. Mas tem umas coisas que não entendo e que devo dizer a todos. Por exemplo, quando entro, com a bandeja do café, na sala de um diretor e ele tá em reunião com outros doutores, ninguém me olha e responde a meu bom dia. Vai só estendendo a mão e pegando a xícara, e não diz nem uma vez, para ser pelo menos diferente, muito obrigado. Tem hora que um me chama, dá um dinheiro e diz pra trazer um maço de cigarros. Eu vou, desço as escalas se o elevador demora, atravesso a rua, compro o cigarro, volto, entrego ao doutor. Aí, outro me diz, entregando uns níqueis, uma caixa de fósforos. Por que não discutiram antes o que queria pra eu fazer tudo de uma vez? Por que subir e descer, descer e subir pra comprar aos pouquinhos? Tem ocasião que eu vou três, quatro vezes fazer comprinhas assim. Agora, acho que essas reuniões vão ajudar todos nós a melhorar as coisas. Eu mesmo tou entendendo muito mais o trabalho de muita gente que eu não sabia o que fazia. Espero que quem nunca 
me disse bom dia ou muito obrigado não tenha ficado zangado comigo, humilde zelador. Contei essas estórias porque elas fazem parte de meu dia a dia, aqui, no DR.” (FREIRE, 2003, p. 133) \{Grifos nossos\}.

É bom lembrar que o relato do Sr. Francisco se remete à década de 1950 do século XX no Brasil. Alguma semelhança com as realidades que persistem nos espaços educativos no século XXI? Quantos personagens como o Sr. Francisco atuam hoje nos nossos ambientes escolares? Qual o significado do trabalho de cada pessoa na ambiência escolar? (...) Tantas e quantas questões podem ser suscitadas mediante a leitura do relato do Sr. Francisco.

$\mathrm{Na}$ sequência do relato do Sr. Francisco, Freire (2003, p. 133) escreve: "O elitismo que nos empapa não nos permite perceber a incoerência entre nossos discursos libertários e o indiferentismo diante de uma pessoa reduzida à condição de quase coisa. E não se diga que isso é um problema menor." \{Grifos nossos\}. Conhecer, reconhecer, ouvir, olhar, acolher, valorizar, orientar, em suma, gerir pessoas com responsabilidade e ética é sem dúvida a primazia de uma gestão democrática eficaz, não tem como organizar uma gestão escolar sem conhecer as pessoas, sem estar com elas, sem dialogar com verdade.

As contradições adversas da sociedade constituída numa fundamentação escravocrata repleta de culturas preconceituosas, que deixaram seu legado de tantos atrasos culturais no que tange o respeito pelas diferenças humanas, por exemplo, persiste até a atualidade. Tais contradições estão presentes no ínterim de nossas escolas, e esses desafios preconceituosos de discriminação, de elitismo precisam ser vencidos pelo conhecimento e pela postura consciente e sábia de pessoas e/ou profissionais comprometidos em tornar as suas ambiências educativas em locais, veementemente, democráticos.

A importância do trabalho de cada pessoa e as tarefas que cada uma delas desenvolve na ambiência escolar explicitam que cada sujeito é relevante para que os processos aconteçam com eficácia. Essa verdade sobre a relevância de cada pessoa no desenvolvimento da escola é algo que precisa ser propagado pelas equipes gestoras, que almejam uma escola democrática. Precisa-se ensinar a todos, refletir com todos, que o trabalho é uma possibilidade de o sujeito interferir na construção de sua sociedade, é como este sujeito adulto traça sua história, constitui suas famílias, etc. Antunes (2009, p. 136) diz: "o trabalho está no centro do processo de humanização do homem.

E como a EPT tem em sua essência o trabalho, cada vez mais compreende-se o crescimento na importância dessa modalidade de ensino nas políticas educacionais brasileiras. $O$ desafio de formar uma geração apta a 
agir, vivenciar e operacionalizar todos os mecanismos envolvidos na esfera de formação profissional, explicita a urgência da constituição da gestão democrática, enquanto possibilidade de formação ampliada.

O exemplo de Paulo Freire como gestor nos indica a relevância dos aprendizados que são constantes na lida com as pessoas nos ínterins dos espaços educacionais. Destaca-se a necessidade de formação constante dos sujeitos frente às realidades educativas que são mutáveis. E diante dos desafios intermináveis das práticas com as diferentes pessoas nos cotidianos da ambiência educativa Freire (2003, p. 145) enfatiza: "A prática precisa da teoria, a teoria precisa da prática, assim como o peixe precisa da água despoluída." Como o papel do gestor democrático requer a lida com as pessoas de maneira mais justa possível, ouvindo e interagindo com responsabilidade mediante a ação das pessoas, é impreterível, que tal gestor esteja sempre se preparando por meio das leituras, do estudo, da pesquisa, da reflexão, como também, atento a tudo e a todos que compõe as suas práticas cotidianas, a fim de avaliá-las constantemente, buscando a melhoria dos processos e alcance cada vez mais democrático de suas ações.

Freire (2003, p. 146) expressa sobre suas experiências vivenciadas no Sesi as seguintes palavras: "Aprendi, na minha passagem pelo Sesi, para nunca mais esquecer, a como lidar com a tensa relação entre prática e teoria."

Em suma, Freire (2003) nos ensina que:

O sonho possível é a democracia em que os desrespeitos se dão, mas os desrespeitadores, quem quer que sejam eles ou elas, são severamente punidos de acordo com a lei. $\mathrm{O}$ acerto ou o valor da democracia não está na santificação de mulheres e de homens, mas na rigorosidade ética com que trata os desvios da própria democracia de que somos capazes como seres históricos, inconclusos, inacabados. Nenhuma democracia pode esperar que sua prática tenha força santificante. A boa democracia adverte, esclarece, ensina, educa, mas também se defende das ações de quem, ofendendo a natureza humana, nega e a rebaixa. (FREIRE, 2003, p. 204) \{Grifos nossos\}.

Não obstante, é preciso prosseguir com responsabilidade e vontade de encontrar novas possibilidades diante das adversidades apregoadas no convívio histórico educacional.

\section{CONSIDERAÇÕES}

Entende-se que a gestão democrática é um instrumento importantíssimo na conjectura de mais espaços igualitários na Ept, a qual, sobremodo, seja equânime frente às reais necessidades dos seus educandos. 
Para exercer a democracia nas práticas educativas é preciso entender a construção histórica, política, social que norteia o caminhar democrático da nossa sociedade, na qual os seus partícipes são aprendizes da tal democracia. Freire (2003) exorta a pensar que:

A luta, no Brasil, pela democracia, passa por uma série de possíveis ângulos a ser política e pedagogicamente tratados - o da justiça, sem a qual não há paz, o dos direitos humanos, o do direito à vida, que implica o de nascer, o de comer, o de dormir, o de ter saúde, o de vestir, o de chorar os mortos, o de estudar, o de trabalhar, o de ser criança, o de crer ou não, o de viver cada um e cada uma a sua sexualidade como bem lhe aprouver, o de criticar, o de discordar do discurso oficial, o de ler a palavra, o de brincar não importa a idade que se tenha, o de ser eticamente informado do que ocorre no nível local, no regional, no nacional e no mundial. O direito de mover-se, de ir e de vir. O direito de não ser discriminado nem do ponto de vista do sexo, da classe, da raça ou por razão qualquer, como por ser demasiado gordo ou gorda ou demasiado magro ou magra. (FREIRE, 2003, p. 204).

Enaltecer as diretrizes democráticas dentro da organização escolar compreende conhecer, reconhecer e lutar a favor do respeito às diferenças, propagando, conscientemente, entre os sujeitos dos âmbitos escolares as reais dificuldades históricas, políticas e sociais que permeiam a conquista da liberdade perante as organizações capitalistas.

Exercer a gestão democrática na contemporaneidade implica lutar para vencer os preconceitos nas ambiências escolares, como também propagar o respeito supremo aos direitos das pessoas serem livres perante suas características singulares.

Vale ressaltar o discorrer de Arroyo (2020) acerca da gestão escolar em nossos dias, que sem dúvida, corrobora com os ideários de Paulo Freire:

Dar centralidade a uma gestão com justiça social exige formar docentes, educadores, gestores que entendam os educandos não apenas como desiguais a administrar políticas de igualdade pela educação. Dar centralidade a administrar vítimas de injustiças sociais é mais radical e mais exigente do que incluir os desiguais. Exige-se uma formação que dê centralidade a entender que injustiças sociais produzem os educandos como vítimas. Entender que injustas estruturas sociais, econômicas, políticas, culturais e até escolares os produzem como injustiçados. Como os padrões sociais, raciais, de gênero, classe os produzem como vítimas. Entender as violências políticas que vêm do Estado, da própria Justiça, das forças da ordem. Formar docentes, educadores, gestores para entender que os injustiçados chegam trazendo em suas vidas as injustiças que padecem e as memórias de seus coletivos injustiçados. Chegam como testemunhas de uma história de tradições autoritárias injustas que pesam sobre eles e seus coletivos étnicos, raciais, de gênero, classe. (ARROYO, 2020, p. 778). \{Grifos nossos\}. 
Isto posto, é relevante enfatizar que: "Um dos papéis das lideranças democráticas é precisamente superar os esquemas autoritários para tomadas de decisão por outros de natureza dialógica.” (FREIRE, 2012, p. 76). Urge, então, dialogar com os sujeitos nas ambiências escolares, a fim de construir consciências críticas e autônomas perante as organizações sociais vigentes. Pois, só então as pessoas autônomas poderão atuar em seus ambientes de vivência com protagonismo, podendo assim, contribuir para a feitura de mundos menos antidemocráticos.

É importante salientar que a postura dialógica é a base de toda a organização da gestão democrática/participativa, na qual todos e todas devem ser respeitados como sujeitos importantes na constituição da identidade escolar, pois se acredita que: "não há diálogo, porém, se não há profundo amor ao mundo e aos homens." (FREIRE, 1987, p. 51).

Por fim, analisando a história da EPT no Brasil, a qual iniciou com uma política de ensino destinado à classe menos favorecida do país e alavancou em uma oportunidade de formação profissional para quem dela usufrui atualmente, faz-se presente o papel contributivo dos professores que na EPT atuam. Considerando que o histórico da formação de professores para a EPT também teve seu marco inicial pautado por um certo descrédito social e ao longo da história recebeu maior comprometimento e incentivo por parte do Governo, visualiza-se um grande compromisso do profissional da educação consciente com o seu papel de educador na formação de um educando não apenas a servir como mão de obra qualificada para o mercado de trabalho, mas também, como um cidadão crítico.

Quiçá, prossiga-se a esperançar-se constantemente, pois a falta de esperança: “(...) nos imobiliza e nos faz sucumbir no fatalismo onde não é possível juntar as forças indispensáveis ao embate recriador do mundo.” (FREIRE, 1992, p. 05).

\section{REFERÊNCIAS}

ANTUNES, Ricardo Luis Coltro. Os sentidos do trabalho: ensaio sobre a afirmação e a negação do trabalho. São Paulo: Boitempo, 2009.

ARROYO, Miguel Gonzalez. Gestão da educação com justiça social. Que gestão dos injustiçados? Revista Brasileira de Política e Administração da Educação (RBPAE), v. 36, n. 2, p. 768 - 788, mai / ago. 2020. Disponível em: https://seer.ufrgs.br/rbpae/article/view/100820/58121 Acesso em: 20/02/2021. 
BRASIL. LDB: Lei de diretrizes e bases da educação nacional. 2 ed. Brasília: Senado Federal, Coordenação de Edições Técnicas, 2018. Disponível em: https:/ / www2.senado.leg.br/bdsf/bitstream/handle/id/544283/lei_de_diretrizes_e_ bases_2ed.pdf Acesso em: 20/01/2021.

BRASIL, Diretrizes Curriculares Nacionais da Educação Básica. Ministério da Educação. Secretaria de Educação Básica. Brasília, 2013. Disponível em: $<$ http://portal.mec.gov.br/index.php?option = com _ docman\&view $=$ download $\& a$ lias $=13448$-diretrizes-curiculares-nacionais-2013pdf\&Itemid=30192> Acesso em: 20/01/2021.

BRASIL. Lei 13.005 de 25 de junho de 2014. Plano Nacional de Educação. Brasília, 2014. Disponível em: <http://pne.mec.gov.br/18-planos-subnacionaisde-educacao/543-plano-nacional-de-educacao-lei-n-13-005-2014> Acesso em: 20/01/2021.

FREIRE, P. Pedagogia do Oprimido. $17^{a}$ ed. Rio de Janeiro: Editora Paz e Terra, 1987.

- Pedagogia da Esperança: um reencontro com a Pedagogia do Oprimido. Notas de Ana Maria Araújo Freire. Rio de Janeiro: Paz e Terra, 1992.

. Educação como prática da liberdade. $27^{\mathrm{a}}$ ed. Rio de Janeiro: Editora Paz e Terra, 2003.

Cartas a Cristina: reflexões sobre minha vida e minha práxis. Direção, organização e notas Ana Maria Araújo Freire. $2^{a}$ ed. São Paulo: Editora UNESP, 2003.

À sombra desta mangueira. Rio de Janeiro: Civilização Brasileira, 2012.

FRIGOTTO, Gaudêncio. Escola "sem” partido: esfinge que ameaça a educação e a sociedade brasileira. Organizador Gaudêncio Frigotto. Rio de Janeiro: UERJ, LPP, 2017. Disponível em: https://fnpe.com.br/wp-content/uploads/2018/11/ gaudencio-frigotto-ESP-LPPUERJ.pdf Acesso em 20/01/2021. 
KUNZE, N.C. O surgimento da rede federal de educação profissional nos primórdios do regime republicano brasileiro in Revista Brasileira da Educação Profissional e Tecnológica /Ministério da Educação, Secretaria de Educação Profissional e Tecnológica. v. 2, n. 2, (nov. 2009 -). - Brasília: MEC, SETEC, 2009.

\section{Sandra Terezinha Urbanetz}

Pós Doutora em Educação pela Universidade do Estado do Rio de Janeiro, Programa de Pós-Graduação em Políticas Públicas e Formação Humana (PPFH - 2013/2014). Pós Doutora pela Faculdade de Psicologia e Ciências da Educação da Universidade do Porto - Portugal (2015). Doutora em Educação pela Universidade Federal do Paraná (2011). Docente do Instituto Federal do Paraná, Campus Curitiba. E-mail: sandra.urbanetz@ifpr.edu.br

\section{Eliana Nunes Maciel Bastos}

Mestre em Educação pelo Instituto Federal do Paraná (2020). Pedagoga e Professora na Rede Municipal de Pinhais/PR. E-mail: elianamaciel1982@gmail. com 